Lobo, J.A. \& Bravo Méndez, Y. (2021). Diversity and foraging patterns of bees on flowers of Cucurbita pepo (Cucurbitaceae) in Costa Rica. Revista de Biología Tropical, 69(2), 494-506. DOI 10.15517/rbt.v69i2.44076

DOI 10.15517/rbt.v69i2.44076

\title{
Diversity and foraging patterns of bees on flowers of Cucurbita pepo (Cucurbitaceae) in Costa Rica
}

Jorge A. Lobo ${ }^{1 *}$; (D) Orcid: 0000-0002-8974-2355

Yanil Bravo Méndez'; (D) Orcid: 0000-0003-2430-7536

1. Escuela de Biología, Universidad de Costa Rica, San José, Costa Rica; jorge.lobo@ucr.ac.cr (*Correspondence); cryanil.bravo@ucr.ac.cr

Received 02-X-2020. Corrected 23-II-2021. Accepted 02-III-2021.

\begin{abstract}
Introduction: The species and functional diversity of pollinators are important components for the reproduction of cultivated plants. More information is necessary about this diversity and its geographical variation in crops such as Cucurbita pepo, an important crop in global agriculture. Objective: To describe the taxonomic diversity, geographic variation and foraging patterns of the community of bees that visit C. pepo crops in Costa Rica. Methods: Squash fields were visited at 11 locations within three geographic regions of the country, where the groups of bees and their relative frequency were determined. Through video recordings, information was obtained on their behavior at two locations. Results: A minimum of 27 species belonging to 19 genera and 2 families of bees were found. Three species were dominant in 10 localities (Eucera limitaris, Apis mellifera and Trigona corvina). Altitude reduces bee diversity due to the dominance of Bombus ephipiatus in high regions. Two genera of halictids (Megalopta and Caenaugochlora) that are rarely reported in this crop were frequently observed. Trigona bees dominated among the flowers later in the morning, lacerating nectary holes to facilitate nectar collection. Conclusions: Squash fields in Costa Rica are visited by a highly diverse bee community, which may ensure pollination via complementarity in the face of spatial or seasonal changes in environmental conditions.
\end{abstract}

Key words: Cucurbita; bees; crop pollination; stingless bees; squash bees; squash.

Temporal and spatial variation in the diversity and composition of the pollinator community of a plant species is a frequent conclusion of pollination studies (Herrera, 1989; Waser, Chittka, Price, Williams, \& Ollerton, 1996; Price, Waser, Irwin, Campbell, \& Brody, 2005; Winfree et al., 2018), although the amplitude of this variation may be restricted to the taxonomic groups favored by the floral syndrome (Rosas-Guerrero et al., 2014). This variation is an important condition for evaluating selection pressures on floral traits (Santiago-Hernández et al., 2019), as well as the diversity of pollinators required for the reproduction of a plant species at a scale larger than a population or locality (Winfree et al., 2018). The quantity and diversity of pollinators plays an important role in the productivity of crops worldwide, particularly in small farms aimed at the production of fruits and vegetables (Hoehn, Tschamtke, Tylianakis, \& Steffan-Dewenter, 2008; Garibaldi et al., 2016; Reilly et al., 2020).

The cultivated species of the genus Cucurbita (Cucurbitaceae) (pumpkin or squash; 
Spanish common names include calabaza, ayote, zapallo, and pipian) comprise a group of five species with a proposed center of origin in North America that have been developed through the domestication of a collection of wild species (Hurd, Linsley, \& Whitaker, 1971). The species of this genus are characterized by being monoecious, with large seasonally produced yellow flowers in which both the staminate and pistillate flowers produce large amounts of nectar. Nectaries are found in a chamber at the base of the stamens in staminate flowers and in a lower ring at the base of the pistil in pistillate flowers (Nepi \& Paccini, 1993; Nepi, Guarnieri, \& Pacini, 2001; Vidal, Jong, Wien, \& Morse, 2006). Therefore, Cucurbita species depend on pollinating agents for their reproduction.

Floral visitors of Cucurbita include several species of the subgenera Eucera (Peponapis) and Eucera (Xenoglossa), which are native to America and have evolved specialization in collecting pollen exclusively from Cucurbita sp. (Hurd et al., 1971). These bees have been identified as the most effective pollinators of wild and cultivated species of Cucurbita, and their current distribution range has been attributed to the expansion of the crop (Hurd et al., 1971). However, across the American continent, these crops are visited by highly diverse bee species, whose composition depends on the species of Cucurbita, geographic region and season of the year (Ashworth \& Galetto, 2001; Meléndez-Ramírez, Magaña-Rueda, Parra-Tabla, Ayala, \& Navarro, 2002; Shuler, Roulston, \& Farris, 2005; Krug, Alves-dosSantos, \& Cane, 2010; Serra \& Campos, 2010; Vidal, Jong, Wien, \& Morse, 2010; Zambrano, Gonzales, Hinojosa-Diaz, \& Engel, 2013; Enríquez, Ayala, Gonzales, \& Nuñez-Farfán, 2015; Phillips \& Gardiner, 2015, DelgadoCarrillo et al., 2018; Pfister, Eckerter, Schirmel, Cresswell, \& Entling, 2017). A review of bee inventories of C. pepo, C. moschata and $C$. maxima flowers (Digital Appendix) shows that nonnative Apis mellifera (nonnative), Eucera and several species of Bombini, Meliponini and Halictidae are the most common groups of bees visiting Cucurbita crops on this continent.

Some studies have analyzed the geographic diversity of the abundance and composition of Cucurbita crop-associated bees showing that factors such as changes in forest cover, the type of management, the area of cultivation, and altitude influence the spatial variation of these bee communities (Meléndez-Ramírez et al., 2002; Shuler et al., 2005; Krug et al., 2010; Serra \& Campos, 2010; Vidal et al., 2010; Zambrano et al., 2013; Enríquez et al., 2015; Phillips \& Gardiner, 2015). Spatial changes in the composition of species that pollinate a crop require the conservation of pollinator diversity at local and regional spatial scales to maintain the ecosystem services provided by local bees at different locations (Winfree et al., 2018), particularly when the pollination services of managed honeybees may be endangered by the decline in their populations (Carreck \& Newman, 2010). These conservation efforts represent a challenge for our societies because of the serious threat of decline of bees due to different causes of human origin (Potts et al., 2010).

In Central America, there have been few studies of the bees associated with Cucurbita crops. In Costa Rica, Wille (1985) found 5 species of the genus Eucera in crops from the Central Valley and Guanacaste, but no information was reported for the other bees associated with these crops. In Guatemala, Enríquez et al. (2015) reported 27 species of bees, belonging to Apidae and Halictidae, visiting these crops in highlands regions. These authors conclude that there is high variation between locations in the composition of species but that a fraction of dominant species may generally ensure the pollination of the crop. Both countries are characterized by great altitudinal and climatic heterogeneity within a relatively small territory, presenting ideal conditions for studying geographic variation in the pollination of crops such as squash.

This study was aimed at increasing our knowledge about the community of visiting bees of Cucurbita pepo crops in the Central American region through an inventory of bees 
in different squash fields in three regions of Costa Rica. The main objective is to determine the taxonomic diversity and composition of bee species visiting Cucurbita pepo crops in different localities in Costa Rica, and their geographic and temporal pattern variation within the study area. These observations would allow us to determine whether the Eucerini species observed by Wille (1985) in Costa Rica can still be found 35 years later. In addition, this study recorded some aspects of intrafloral behavior of dominant species that may be related to pollinator potential. These observations would let us to understand better the importance of bee diversity as a pollinator of this crop in Neotropical regions.

\section{MATERIALS AND METHODS}

Study locations: During the years 20162019, collections were carried out in Costa Rica in different squash fields in the Central Valley (7 locations), in Guanacaste Province (2 locations) and in the Western sector of the Talamanca mountain range ( 2 locations). The landscape characteristics, climate and altitude of each location are presented in Table 1. Local climatic conditions were obtained from regional climatic analysis of the Costa Rican National Meteorological Institute (CRRH, 2008). In these locations cultivation of Cucurbita pepo is done without irrigation, which limits the growth and flowering of the crop to the rainy season (May-November). C. moschata, another squash

TABLE 1

Sampling sites of Cucurbita pepo bees in Costa Rica, with biophysical and landscape characteristics of each location

\begin{tabular}{|c|c|c|c|c|c|c|}
\hline Region & Locality & $\begin{array}{l}\text { Geographic } \\
\text { Coordinates }\end{array}$ & $\begin{array}{l}\text { Altitude } \\
\text { (m.a.s.1) }\end{array}$ & $\begin{array}{c}\text { Annual } \\
\text { Precipitation }(\mathrm{mm}) / \\
\text { Rainy days }\end{array}$ & $\begin{array}{l}\text { Dimension of } \\
\text { the squash field }\end{array}$ & $\begin{array}{l}\text { Landscape } \\
\text { features }\end{array}$ \\
\hline \multirow[t]{7}{*}{$\begin{array}{l}\text { Central } \\
\text { Valley }\end{array}$} & Piedades & $\begin{array}{l}9^{\circ} 56^{\prime} 10^{\prime \prime} \mathrm{N} \\
84^{\circ} 13^{\prime} 26^{\prime \prime} \mathrm{W}\end{array}$ & 818 & $1947 / 145$ & Large & $\begin{array}{l}\text { Semiurban/ } \\
\text { gallery forest }\end{array}$ \\
\hline & Cerro Colón & $\begin{array}{l}9^{\circ} 54^{\prime} 42^{\prime \prime} \mathrm{N} \\
84^{\circ} 13^{\prime} 03^{\prime \prime} \mathrm{W}\end{array}$ & 1120 & - & Large & $\begin{array}{l}\text { Pastures/ } \\
\text { Forest fragments }\end{array}$ \\
\hline & Acosta & $\begin{array}{l}9^{\circ} 46^{\prime} 8^{\prime \prime} \mathrm{N} \\
84^{\circ} 12^{\prime} 22^{\prime \prime} \mathrm{W}\end{array}$ & 760 & $2370 / 149$ & Medium & $\begin{array}{l}\text { Pastures/ } \\
\text { Forest fragments }\end{array}$ \\
\hline & Sta Cecilia & $\begin{array}{l}10^{\circ} 2^{\prime} 5^{\prime \prime} \mathrm{N} \\
84^{\circ} 2^{\prime} 17^{\prime \prime} \mathrm{W}\end{array}$ & 1520 & $2531 / 152$ & Small & $\begin{array}{l}\text { Pastures/ } \\
\text { Forest fragments }\end{array}$ \\
\hline & Pacayas & $\begin{array}{l}9^{\circ} 54^{\prime} 24^{\prime \prime} \mathrm{N} \\
83^{\circ} 47^{\prime} 42^{\prime \prime} \mathrm{W}\end{array}$ & 1760 & $2245 / 193$ & Small & $\begin{array}{l}\text { Pastures/ } \\
\text { Crops }\end{array}$ \\
\hline & Cervantes & $\begin{array}{l}9^{\circ} 53^{\prime} 13^{\prime \prime} \mathrm{N} \\
83^{\circ} 47^{\prime} 42^{\prime \prime} \mathrm{W}\end{array}$ & 1250 & $2000 / 193$ & Large & Crops \\
\hline & Juan Viñas & $\begin{array}{l}9^{\circ} 53^{\prime} 37^{\prime \prime} \mathrm{N} \\
83^{\circ} 44^{\prime} 28^{\prime \prime} \mathrm{W}\end{array}$ & 1200 & $1675 / 163$ & Small & Pastures/Crops \\
\hline \multirow[t]{2}{*}{ Guanacaste } & Cuajiniquil & $\begin{array}{l}10^{\circ} 56^{\prime} 08^{\prime \prime} \mathrm{N} \\
85^{\circ} 41^{\prime} 13^{\prime \prime} \mathrm{W}\end{array}$ & 15 & $1517 / 89$ & Medium & Pastures \\
\hline & Sta Cruz & $\begin{array}{l}10^{\circ} 10^{\prime} 13^{\prime \prime} \mathrm{N} \\
85^{\circ} 32^{\prime} 15^{\prime \prime} \mathrm{W}\end{array}$ & 675 & $2116 / 89$ & Small & $\begin{array}{l}\text { Crops/ } \\
\text { Forest fragments }\end{array}$ \\
\hline \multirow[t]{2}{*}{ Talamanca } & La Cangreja & $\begin{array}{l}9^{\circ} 47^{\prime} 45^{\prime \prime} \mathrm{N} \\
83^{\circ} 57^{\prime} 20^{\prime \prime} \mathrm{W}\end{array}$ & 1830 & $1751 / 182$ & Small & $\begin{array}{l}\text { Crops/Pastures/ } \\
\text { Fragments forests }\end{array}$ \\
\hline & La Cima & $\begin{array}{l}\text { 9039'34" N } \\
83^{\circ} 54^{\prime} 54^{\prime \prime} \mathrm{W}\end{array}$ & 2146 & $2632 / 192$ & Large & $\begin{array}{l}\text { Crops/Pastures/ } \\
\text { Primary forests }\end{array}$ \\
\hline
\end{tabular}

\footnotetext{
* - Small $(<20)$, medium $(20-200)$, large $(>200$ open flowers at the time of collection).
} 
species cultivated in Costa Rica, is grown under the same time schedule of $C$. реро in Costa Rica. Flowering peak commonly occurs between May to August, period when sampling of bees was done. The maximum distance between two locations, except Cuajiniquil, Guanacaste, was $50 \mathrm{~km}$. Cuajiniquil is located approximately $190 \mathrm{~km}$ from the Central Valley. The minimum distance was $5 \mathrm{~km}$. Most of the localities were grouped in the Central Valley and Cordillera de Talamanca, relatively close to one another, but with important contrasting values of altitude and precipitation (Table 1). Most of the sampling sites were in agricultural regions with high forest fragmentation, where forest patches subsist as gallery forests of different sizes, with the exception of La Cima de Dota and Santa Cruz, where agricultural farms close to protected areas with mature or secondary forests were visited. Another important variable was the number of open flowers at the time of sampling, with localities ranging from small family crops $(<20$ open flowers at the time of collection) to farm crops with more than 200 open flowers. The diversity and abundance of bees attracted to these sites may be influenced by the size of the floral display. Wild Cucurbita species or others domesticated Cucurbita crops were not observed near the visited farms.

Bee collection and counting: At each site, a collection of bees was obtained from 5:00-9:00 am. Bees were trapped in male and female flowers, although most of the samples were collected in male flowers because of their higher frequency. The squash field was explored for periods of $15 \mathrm{~min}$, during which all the bees observed in flowers were collected except for Apis mellifera, Trigona and Bombus species. These species were common and easy to identify in the field; thus, only the number of individuals in the flowers during each census was registered. The maximum number of individuals counted in a census was used as an estimate of the local abundance of these species. All collections were performed on sunny days. As the composition of species can change with the time of the day, 6 collections were performed, distributed among early (4:45-5:00 am; 5:15-5:30 am), middle (5:45-6:00 am; 6:15-6:30 am) and late hours (6:45-7:00 am; 7:30-8:45 am). The last time interval was a somewhat longer than the others because we observed that species composition remained stable after 7:00 a.m. (see below). It was observed that bee activity declines drastically after 9:00 a.m. At that time, most of the flowers were dominated by Trigona bees with few visits by other species, or there were no visits at all. Some localities (Piedades, Cerro Colón, La Cima de Dota and Sta Cruz) were visited once more approximately 1 week later. No new species were observed in samples obtained in these visits. It was also observed that abundance estimates of each species were approximately repeated on the second survey. It was concluded that the sampling effort was enough to obtain good estimates of bee taxonomic diversity and species composition in the studied localities for the specific flowering period. To homogenize between localities, the abundance data obtained in the first sampling were selected in the localities visited twice. All bees were identified to the species level except Agapostemon and Augochlora. Identification was performed using available taxonomic keys and the collection of the Zoology Museum of the Escuela de Biología, Universidad de Costa Rica, where voucher specimens were deposited. Eucera (Peponapis) specimens were sent to the Bee Biology and Systematics Laboratory (Utah) to help with identification.

In some localities, Piedades and Cerro Colón, there are two squash crops per year, one in the middle (August-September) and another at the end of the rainy season (NovemberDecember). To determine if composition of the floral visitors changes between crop seasons, sampling was performed during each crop season in Piedades, one in August 2019 and another in November of the same year, following the same collection intensity protocols and observation times.

Intrafloral behavioral observations: To determine whether the different floral visitors made contact with the reproductive parts of 
the flowers and to obtain observations of the foraging behavior of each group of bees inside the flowers, continuous video recordings were performed in flowers from 5:00 am until 7:30 am at two localities (Piedades and La Cima de Dota). Sony HDRCX700 Handycam video cameras (San Diego, CA, USA) were used. The recordings ended at 7:30 am because after this time no significant changes were detected in the activity pattern of the bees, except for their near disappearance from the flowers after 10:00 a.m. when many flowers showed signs of wilting. Six male and five female flowers were chosen for filming in La Cima de Dota in August 2016, and the same number of flowers were chosen in the town of Piedades in August 2019. This comparison allowed us to visualize the differences in behavior between localities with different floral visitors (see below). A total of $6 \mathrm{~h}$ of video recordings were obtained in each location, which were manually analyzed to check the foraging schedule and the behavior of different bees in each location. Special attention was paid to the pollen load (large $=$ body densely covered by pollen, intermediate $=$ presence of scattered pollen, more visible in corbiclae/escopae; small = pollen scattered with few or no grains) and the visit duration. A sample of 2-3 individuals of bee species observed at flowers were collected and their pollen loads visualized in a microscopy to check if it were Cucurbita pollen.

Statistical analysis: Mean values and confidence intervals of species richness (number of species) for each locality and altitudinal level were obtained by bootstrapping with 300 replicates (Hsieh, Ma, \& Chao, 2016). We grouped locations in three altitude categories: low ( $<1000$ m.a.s.l. 5 localities), intermediate (1000-1 800 m.a.s.l. 5 localities) and high (> 1800 m.s.a.l. 2 localities). A generalized linear model with a Poisson distribution was used to test the effect of altitude on species richness using altitude as a categorical variable. To test differences in the composition (abundance of each species) of the bee community at different altitudes a Multivariate Analysis of
Variance with permutations (PERMANOVA) was performed using the Bray-Curtis distance, as implemented in the vegan package (Oksanen et al., 2019).

\section{RESULTS}

Diversity and geographic variation: The species collected and their order of dominance (frequency rank order, $1=$ most frequent, $8=$ least frequent) at each locality are shown in Fig. 1. Some localities had very low visitation rates (Juan Viñas and Santa Cecilia), which is reflected in the low number of bees collected from those locations. In total, individuals belonging to 19 genera and 2 families (Halictidae and Apidae) of bees were obtained. From the samples identified to the species level, a total of 22 species were obtained, while 5 groups of bees were only identified to the genus level, for a minimum total number of 27 species. The number of species could increase by 2-3 if genera such as Augochlora (very diverse) or Agapostemon were identified to the species level. The presence of 2 species of the genus Megalopta as well as one species of Caenaugochlora ( $C$. costaricensis) at high levels of dominance, was noted at 5 and 4 locations, respectively.

Abundant species were observed in most localities (Fig. 1): 2 species of Meliponini tribe: Trigona corvina and Partamona orizabaensis, honey bees (Apis mellifera) and a species of bee specialized on this crop, Eucera (Peponapis) limitaris. A. mellifera workers observed in the crops are probably originated from feral colonies, as no commercial beekeeping was observed near the studied crops. Other species were frequent only in some locations: i) Bombus ephipiatus was the most frequent floral visitor in La Cima de Dota, the highestaltitude location but was rare or absent in other locations; ii) in Cuajiniquil (Guanacaste) and Acosta, Eucera (Peponapis) crassidentata was frequent. Among the two subgenera of bees specialized on Cucurbita, four species of Eucera (Peponapis) (E. limitaris, E. crassidentata, E. utahensis and E. apiculata) 


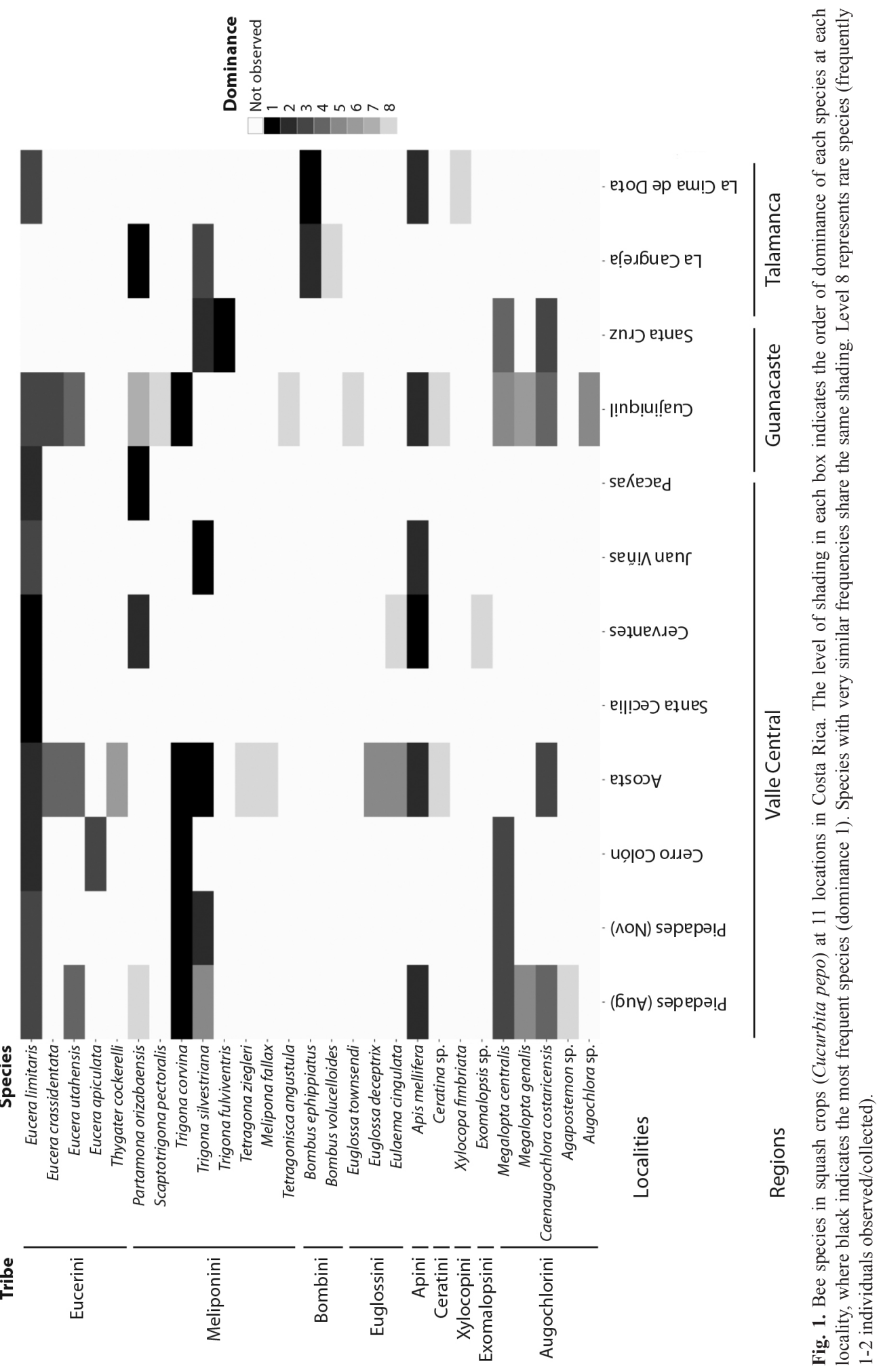


were collected, the last of which was only collected in one locality (Cerro Colón) as a rare species (Fig. 1).

Large differences in species richness were found between localities (Fig. 2). The localities with the highest species richness (species richness 10.5-15.2), were Piedades (Aug), Acosta and Cuajiniquil, which were found at altitudes less than $1000 \mathrm{~m}$. a. s. 1. in medium-large crops and in drier climatic regimes. Small crops (La Cangreja, Juan Viñas, Sta Cecilia, and Pacayas) showed lower species diversity (species richness 1-4), although low diversity was also found in a large crop in highland regions (La Cima de Dota) (species richness 4). Crops located at low altitude levels presented higher species richness compared to medium $(\mathrm{Z}=-3.897, \mathrm{P}<0.001)$ and high altitudes $(\mathrm{Z}$ $=-2.174, \mathrm{P}<0.05)$ PERMANOVA analysis showed that bee species composition changed significantly between altitude levels $(\mathrm{F}=2.03$, $\mathrm{R}^{2}=0.31$, d.f. $=2,9, \mathrm{P}<0.01$ ).

At Piedades, the two sequential collections corresponding to the two annual crops separated by 3 months (August and November) showed changes in the abundance and order of dominance of the species (Fig. 1). In November, a frequent species (Apis mellifera) and several rare species (Agapostemon sp., M. genalis, and E. utahensis) observed in August disappeared, reducing the number of species from 10 to 4 as well as the abundance of bees collected in flowers (150 to 45). In November, $T$. corvina frequency was $95 \%$ of the samples, while in August this figure was approximately $60 \%$.

Behavior of common species: Table 2 summarizes the main observations of 5 of the most common floral visitors of $C$. pepo in the visited localities. All of these species touched the reproductive parts of male and female flowers. The largest and hairiest species (Eucera and Bombus) and those that visit male flowers earlier (Megalopta) were the ones that most frequently carry large pollen loads classified as "large". A temporal sequence of foraging was observed, in which the crepuscular Megalopta sp. begins at 4:30 am (observed before the initiation of the recordings), followed by the arrival of Apis mellifera, Eucera and Bombus,

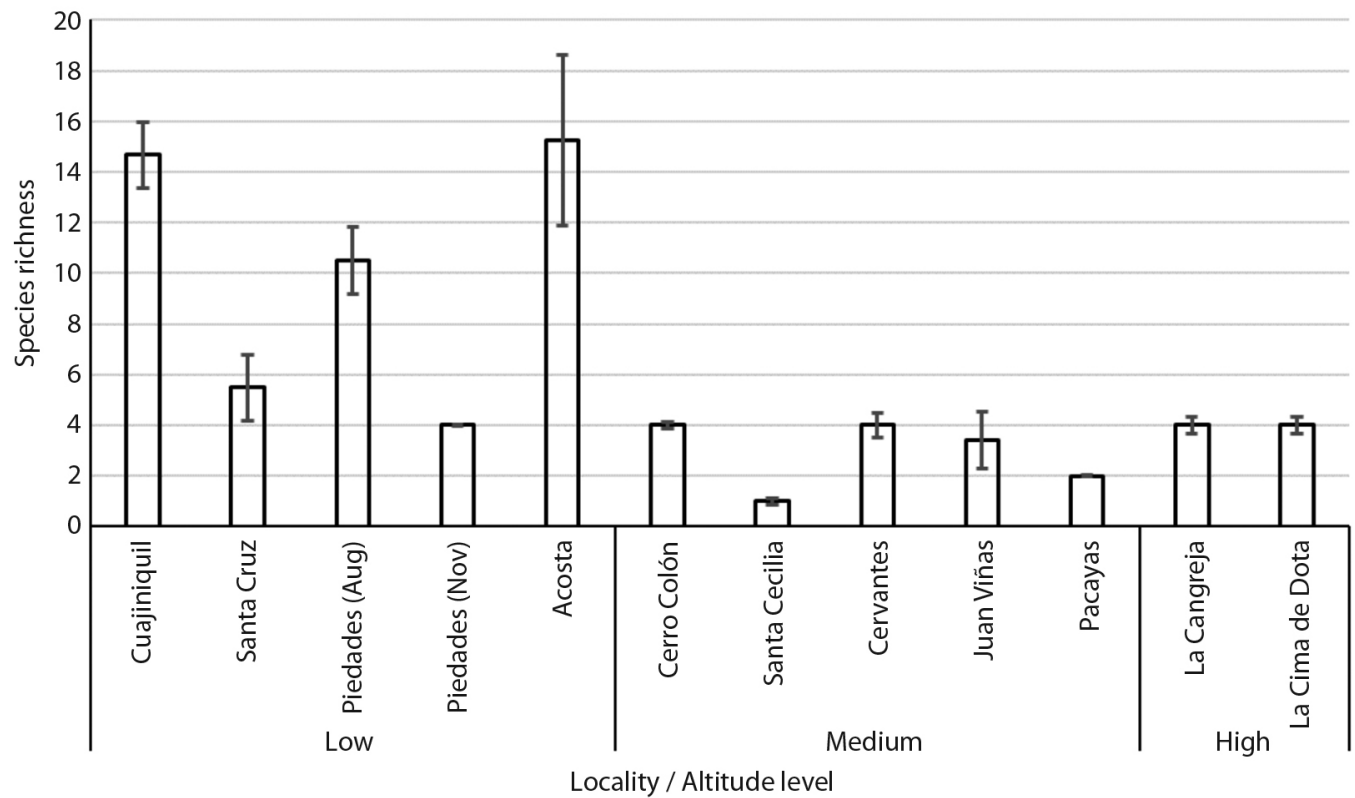

Fig. 2. Species richness of bee populations visiting C. pepo crops in each locality studied. Localities are grouped by altitude level (low 0-1 000 m.a.s.l., medium 1000-1800, high > 1800). Mean values and confidence intervals were obtained by bootstrapping. 




Fig. 3. Nectary pores in male C. pepo flowers. A. normal, B. enlarged by T. corvina bites.

TABLE 2

Behavioral patterns of the most common bee visitors of $C$. pepo in Costa Rica obtained from video recordings in two locations. See Methods for the classification of the pollen load and duration of visits

\begin{tabular}{|c|c|c|c|c|c|}
\hline \multirow[b]{2}{*}{ Bee taxa } & \multirow[b]{2}{*}{$\begin{array}{l}\text { Pollen } \\
\text { load }\end{array}$} & \multicolumn{2}{|c|}{ Time of foraging } & \multirow{2}{*}{$\begin{array}{l}\text { Median of duration of } \\
\text { visit in seconds (s) } \\
\text { (interquartile range) }\end{array}$} & \multirow[b]{2}{*}{ Observations } \\
\hline & & $\begin{array}{l}\text { First individuals } \\
\text { observed }\end{array}$ & $\begin{array}{l}\text { Last individuals } \\
\text { observed }\end{array}$ & & \\
\hline Eucera (Peponapis) sp. & Large & 5:00 a.m. & $\begin{array}{l}\text { rare after } \\
7 \text { a.m. }\end{array}$ & $18(5-62)$ & $\begin{array}{l}\text { Fast flights between } \\
\text { flowers. }\end{array}$ \\
\hline Megalopta sp. & Large & 4:30 a.m. & 6 a.m. & $225(51-518)$ & $\begin{array}{l}\text { First floral visitor, starts } \\
\text { foraging at the beginning } \\
\text { of anthesis of male } \\
\text { flowers. }\end{array}$ \\
\hline Bombus sp & Large & 5:00 a.m. & 10 a.m. & $16(7-30)$ & $\begin{array}{l}\text { Fast flights between } \\
\text { flowers. }\end{array}$ \\
\hline Trigona corvina & Small & 5:30 a.m. & $12 \mathrm{~m}$. & $73(39-106)$ & $\begin{array}{l}\text { Group recruitment. } \\
\text { Predominate at flowers } \\
\text { from 6-7 a.m. Aggressive. } \\
\text { Enlargement of the pores } \\
\text { of the floral nectary. }\end{array}$ \\
\hline Apis mellifera & $\begin{array}{l}\text { Medium- } \\
\text { Small }\end{array}$ & 5:00 a.m. & $12 \mathrm{~m}$. & $27(9-45)$ & Non-aggressive behavior. \\
\hline
\end{tabular}

among which the last genus was only observed in highland areas. Different species of Trigona or Partamona, especially Trigona corvina, arrive somewhat later but quickly invade the area around the nectaries of almost all flowers. Megalopta and Trigona bees tend to spend long times collecting nectar (Table 2). Trigona bees exhibit two interesting foraging behaviors: i) they enlarge the nectar chamber pores with their jaws (Fig. 3) seeking nectar, ii) they tend to repel other bees from flowers, because of their abundance and activity, and on rare occasions, by direct attacks. Eucera (Peponapis), Bombus and A. mellifera are characterized by short visits (16-27 s) and quick flights to flowers (Table 2). 


\section{DISCUSSION}

\section{Bee diversity within and between localities}

The data obtained in this study agree with other studies carried out in various locations in the Neotropics (Digital Appendix), showing how different species of Cucurbita are visited by a diverse spectrum of bee species, where the species specialized for the collection of pollen from cucurbits are not always the most frequent (Canto-Aguilar \& Parra-Tabla, 2000; Meléndez-Ramírez et al., 2002; Zambrano et al., 2013; Enríquez et al., 2015; DelgadoCarrillo et al., 2018). The groups collected in Costa Rica have been observed in these studies, such as Trigona, Bombus, Augochlora, Ceratina, Eucera (Peponapis), and Africanized bees (Apis mellifera), along with other rarer groups. These inventories have shown a group of dominant and widely distributed species in this crop, accompanied by a series of rare species with more restricted distributions.

Variations between localities in the degree of alteration of the natural habitat and the intensity of agricultural practices have been mentioned as factors that explain changes in the composition of bees species related to squash fields (Krug et al., 2010; Enríquez et al., 2015). However, Meléndez-Ramírez et al. (2002) found a high diversity of bees that visit cucurbit crops in locations with high degradation of their natural flora. To study the factors that determine changes in the composition of bee species that visit squash in Costa Rica would require a more extensive and systematic sampling of localities under variable conditions of habitat alteration. However, certain general trends can be reported. In our study, an important effect of altitude was detected in the composition and species richness of squash fields. A large crop at more than 2000 m elevation (La Cima de Dota) showed a strong reduction in species richness, while localities at low elevations showed a greater number of species. Hoiss, Krauss, Potts, Roberts and SteffanDewenter (2012) have shown how altitude acts as an environmental filter on diversity in bee communities. In Costa Rica, pollination of $C$. pepo at high elevations seems to be ensured by the abundance of B. ephippiatus. Different species of Bombus have been reported as among the main pollinators of Cucurbita in temperate regions (Shuler et al., 2005, Petersen, Reiners, \& Nault, 2013). The effect of changes in altitude can be seen when bees visiting squash plantations are compared between two locations that are very close spatially (Cerro Colón and Piedades, $5 \mathrm{~km}$ ) but differ by $200 \mathrm{~m}$ in altitude. These localities show strong differences in the composition of bee species, particularly, the presence of Eucera (Peponapis) apiculata at only the highest locality. Changes in the characteristics of the life zones are also important, as evidenced by the exclusive presence of the Eucera (Peponapis) crassidentata species in dry forest (Cuajiniquil), an observation previously reported by Wille (1985). Another factor that seems relevant is the size of the crop since in small crops the species richness is lower. However, in these small crops the presence of Eucera (Peponapis) limitaris is constant. This species seems to be ensuring the pollination of small crops of $C$. pepo, even in deforested regions and under strong agricultural pressure (such as Pacayas and Juan Viñas).

Changes in the composition of pollinators in collections spaced 3 months apart during the rainy season were observed in Piedades. The dominance of social bees of the genus Trigona increased in the second sampling. This variation shows the importance of diversity in the pollination of this crop, where meliponine bees could be ensuring production during times of population decline of other species. The importance of pollinator complementarity during different seasons of a crop has been studied by Delgado-Carrillo et al. (2018) for Cucurbita moschata and by Genung et al. (2017) for other crops.

\section{Bee species rarely reported in Cucurbita crops}

This is the first study to show the use of Cucurbita pepo as a resource by bees of 
the genus Megalopta, bees with the ability to forage during twilight (Wcislo et al., 2004). Megalopta were found at high frequencies in several locations in our study. Some species of this genus show social polymorphism (Wcislo et al., 2004). In this study, two species of Megalopta that show facultative eusociality were found, and it was observed that Cucurbita nectar is used by macro- and microcephalic individuals of both species, which reveals that it is a resource used by potential workers and queens. Another genus not reported previously in C. pepo flowers is Caenaugochlora, a rare bee distributed between Mexico and Northern South America (Michener, McGinley, \& Danforth, 1994). Of the various bee inventories in squash plantations in the Neotropics, only Meléndez-Ramírez et al. (2002) have reported the collection of 1 individual of this genus in the Yucatán. However, in this study, it was observed in flowers of $C$. реро at different locations; it was among the 3 or 4 most frequent species and practiced early foraging on male flowers. Both Megalopta and Caenaugochlora belong to Halictidae, a family with various species reported in crops of different Cucurbita species, but where this family was represented by other genera, such as Augochlora, Lasioglossum, Augochloropsis and Agapostemon (Canto-Aguilar \& Parra-Tabla, 2000; Meléndez-Ramírez et al., 2002; Zambrano et al., 2013; Enríquez et al., 2015; Delgado-Carrillo et al., 2018). These groups were relatively rare or absent in our collections. In a study of the social behavior of Halictidae in Costa Rica, Michener and Kerfoot (1967) observed the presence of Caenaugochlora costaricensis (formerly known as Pseudoaugochloropsis costaricensis) exclusively in Cucurbita flowers. Megalopta bees excavate their nests in dead wood, most frequently in fallen tree branches in the understory (Wcislo et al., 2004). C. costaricensis is a ground-nesting species whose nests have been found in slope banks in roadsides sites (Michener \& Kerfoot, 1967). Therefore, these species have different nesting sites. Their presence in squash cultures is favored by small forest fragments, isolated trees and secondary growth nearby farms in the localities where these bee species were found.

\section{Comparison with earlier Costa Rican Eucerini bees surveys}

The same species of the subgenus Peponapis reported in this study were observed by Wille in 1985 (Wille, 1985). This stability may be due to the continuous presence of Cucurbita crops in the Central Valley and Guanacaste since 1985 as well as the relative capacity of these species to adapt to rural landscapes, especially small crops, where ground nesting areas are available (Phillips \& Gardiner, 2015; Delgado-Carrillo et al., 2017). However, in Guanacaste no individuals of Eucera (Xenoglossa) gaabi, a species reported by Wille (1985), were observed. More collections in Guanacaste are necessary to confirm the possible loss of this species. It is interesting to note that recent inventories of bees in Cucurbita plantations in Mexico have not reported the presence of Xenoglossa subgenus (MeléndezRamírez et al., 2002, Delgado-Carrillo et al., 2018, Digital Appendix), even though Hurd and Linsley (1966) showed that Mexico was part of the natural distribution of these species.

\section{Behavioral observations}

The various floral visitors observed in this study display differences in foraging strategies. Eucera (Peponapis) and Bombus practice a type of foraging characterized by rapid exploration and extraction of nectar from each flower, allowing them to visit many flowers per unit of time (pers. obs.). This strategy, combined with an early foraging schedule, dense hair and relatively large size, makes these bees very efficient potential pollinators of different species of Cucurbita (Canto-Aguilar \& Parra-Tabla, 2000; Serra \& Campos, 2010; Delgado-Carrillo et al., 2018). Megalopta and Caenaugochlora, although not large or hairy bees, visit flowers very early, taking advantage of the onset of nectar flow in male flowers, which also makes them potential pollinators. A very different pattern was observed in Trigona, 
particularly in $T$. corvina. These bees monopolize the flowers shortly after the start of foraging, practicing a slower and more detailed exploration of flower resources, including the slight laceration of the pores leading to the nectar chamber. The congregation of $T$. corvina bees near the nectar chamber sometimes repels other larger bees from 7-8 a.m., such as Apis mellifera and Eucera (Peponapis). These characteristics of Trigona foraging on Cucurbita flowers were also noted by Serra and Campos (2010) in Brazil.

In summary, crops of $C$. pepo in Costa Rica are visited by diverse bees, among which some species may be the main pollinators and others play a secondary role. The importance level of each species in the pollination may be determined by the abundance of each species, their foraging schedule and efficiency in pollen transfer (Herrera 1987; Herrera 1989). This diversity allows the crop to be productive throughout different geographic and seasonal environments (Delgado-Carrillo et al., 2018; Hoehn et al., 2008). It could be suggested that the pollination of this crop is maintained in different geographical regions and different times of the year thanks to the spatial and temporal complementarity of pollination services by different species of bees. More information on the pollinating role of Trigona bees would allow a better understanding of the regulatory factors related to the productivity of this crop. The preservation of nesting sites and diverse floral resources (represented by other crops or wild plant species) are crucial factors to maintain the diverse bee community associated with cultivated Cucurbita, which is very important in the diet and regional culture of the Americas.

Ethical statement: authors declare that they all agree with this publication and made significant contributions; that there is no conflict of interest of any kind; and that we followed all pertinent ethical and legal procedures and requirements. All financial sources are fully and clearly stated in the acknowledgements section. A signed document has been filed in the journal archives.

\section{ACKNOWLEDGMENTS}

We thank deeply to the farmers and their families who gave us guidance and allowed us to collect bees in their gardens. We would like to especially thank Heiner Morales who provided us with his garden in Piedades to enable more detailed analysis of the behavior of bees. J. García, M. Chavarría and F. Pacheco collaborated with the authors in contacting crop owners. G. Jones provided facilities for field work in Sta. Cruz. T. Griswold and C. Ritner collaborated in the identification of bees.

\section{RESUMEN}

\section{Diversidad y patrones de búsqueda de alimento de las abejas en flores de Cucurbita pepo (Cucurbitaceae) en Costa Rica}

Introducción. Dada la importancia del componente diversidad para la polinización de plantas cultivadas, es necesario obtener más información de esta diversidad y su variación geográfica en cultivos como Cucurbita pepo, uno de los cultivos más importantes de la agricultura centroamericana. Objetivo: Describir la diversidad y la variación geográfica de la comunidad de abejas que visitan este cultivo en Costa Rica, y algunos aspectos de sus patrones de búsqueda de alimento. Métodos: Se visitaron cultivos de $C$. pepo en 11 localidades dentro de tres regiones geográficas de Costa Rica, donde se determinó los grupos de abejas y su frecuencia relativa. Por medio de grabaciones de video se registró el comportamiento de cada grupo en dos localidades. Resultados: Fueron encontradas un mínimo de 27 especies pertenecientes a 19 géneros y 2 familias de abejas. Tres especies son dominantes en 10 localidades (Eucera limitaris, Apis mellifera y Trigona corvina). La altitud reduce la diversidad de abejas debido a la dominancia de Bombus ephipiatus en regiones altas. Se observaron dos géneros de halíctidos (Megalopta y Caenaugochlora) no previamente reportados en este cultivo. Abejas Trigona dominan las flores en horarios más tardíos de la mañana, donde algunas veces muerden los orificios de los nectarios para facilitar la recolecta de néctar. Conclusiones: La diversidad de abejas que visitan $C$. pepo en Costa Rica parece asegurar su polinización ante cambios espaciales o estacionales en condiciones ambientales. 
Palabras clave: Cucurbita; abejas; polinización de cultivos; abejas sin aguijón; abejas de las calabazas, abejas sin aguijón; calabazas; ayote.

\section{REFERENCES}

Ashworth, L., \& Galetto, L. (2001). Pollinators and reproductive success of the wild cucurbit Cucurbita maxima ssp. andreana (Cucurbitaceae). Plant Biology, 3(4), 398-404.

Canto-Aguilar, M.A., \& Parra-Tabla, V. (2000). Importance of conserving alternative pollinators: assessing the pollination efficiency of the squash bee, Peponapis limitaris in Cucurbita moschata (Cucurbitaceae). Journal of Insect Conservation, 4(3), 201-208.

Carreck, N., \& Neumann, P. (2010). Honey bee colony losses. Journal of Apicultural Research, 49(1), 1-6.

Delgado-Carrillo, O., Lopezaraiza-Mikel, M., Ashworth, L., Aguilar, R., Lobo, J.A., \& Quesada, M. (2017). A scientific note on the first record of nesting sites of Peponapis crassidentata (Hymenoptera: Apidae). Apidologie, 48(5), 644-647.

Delgado-Carrillo, O., Martén-Rodríguez, S., Ashworth, L., Aguilar, R., Lopezaraiza-Mikel, M., \& Quesada, M. (2018). Temporal variation in pollination services to Cucurbita moschata is determined by bee gender and diversity. Ecosphere, 9(11), e02506.

Enríquez, E., Ayala, R., Gonzalez, V.H., \& Núñez-Farfán, J. (2015). Alpha and beta diversity of bees and their pollination role on Cucurbita pepo L. (Cucurbitaceae) in the Guatemalan cloud forest. The PanPacific Entomologist, 91(3), 211-222.

Garibaldi, L.A., Carvalheiro, L.G., Vaissière, B.E., Gemmill-Herren, B., Hipólito, J., Freitas, B.M., . . . Zhang, H. (2016). Mutually beneficial pollinator diversity and crop yield outcomes in small and large farms. Science, 351(6271), 388-391.

Genung, M.A., Fox, J., Williams, N.M., Kremen, C., Ascher, J., Gibbs, J., \& Winfree, R. (2017). The relative importance of pollinator abundance and species richness for the temporal variance of pollination services. Ecology, 98(7), 1807-1816.

Herrera, C.M. (1987) Components of pollinator 'quality': comparative analysis of a diverse insect assemblage. Oikos, 50, 79-90.

Herrera, C.M. (1989) Pollinator abundance, morphology and flower visitation rate: Analysis of the 'quantity' component in a plant-pollinator system. Oecologia, $80,241-248$.

Hoehn, P., Tscharntke, T., Tylianakis, J.M., \& SteffanDewenter, I. (2008). Functional group diversity of bee pollinators increases crop yield. Proceedings of the Royal Society B: Biological Sciences, 275(1648), 2283-2291.

Hoiss, B., Krauss, J., Potts, S.G., Roberts, S., \& SteffanDewenter, I. (2012). Altitude acts as an environmental filter on phylogenetic composition, traits and diversity in bee communities. Proceedings of the Royal Society B: Biological Sciences, 279(1746), 4447-4456.

Hsieh, T.C., Ma, K.H., \& Chao, A. (2016). iNEXT: an R package for rarefaction and extrapolation of species diversity (Hill numbers). Methods in Ecology and Evolution, 7(12), 1451-1456.

Hurd, P.D., \& Linsley, E.G. (1966). The Mexican squash and gourd bees of the genus Peponapis (Hymenoptera: Apoidea). Annals of the Entomological Society of America, 59(4), 835-851.

Hurd, P.D., Linsley, E.G., \& Whitaker, T.W. (1971). Squash and gourd bees (Peponapis, Xenoglossa) and the origin of the cultivated Cucurbita. Evolution, 25(1), 218-234.

CRRH (Comité Regional de Recursos Hidráulicos). (2008). Clima, variabilidad y cambio climático en Costa Rica. Costa Rica: Comité Regional de Recursos Hídráulicos.

Krug, C., Alves-dos-Santos, I., \& Cane, J. (2010). Visiting bees of Cucurbita flowers (Cucurbitaceae) with emphasis on the presence of Peponapis fervens smith (Eucerini--Apidae) -Santa Catarina, Southern Brazil. Oecologia Australis, 14(1), 128-139.

Meléndez-Ramirez, V., Magaña-Rueda, S., Parra-Tabla, V., Ayala, R., \& Navarro, J. (2002). Diversity of native bee visitors of cucurbit crops (Cucurbitaceae) in Yucatán, México. Journal of Insect Conservation, 6(3), 135-147.

Michener, C.D., \& Kerfoot, W.B. (1967). Nests and social behavior of three species of Pseudaugochloropsis (Hymenoptera: Halictidae). Journal of the Kansas Entomological Society, 40, 214-232.

Michener, C.D., McGinley, R.J., \& Danforth, B.N. (1994). The bee genera of North and Central America (Hymenoptera: Apoidea). Smithsonian Institution Press: Washington, DC, USA.

Nepi, M., \& Pacini, E. (1993). Pollination, pollen viability and pistil receptivity in Cucurbita pepo. Annals of Botany, 72(6), 527-536.

Nepi, M., Guarnieri, M., \& Pacini, E. (2001). Nectar secretion, reabsorption, and sugar composition in male and female flowers of Cucurbita pepo. International Journal of Plant Sciences, 162(2), 353-358.

Oksanen, J., Blanchet, F.G., Friendly, M., Kindt, R., Legendre, P., McGlinn, D., Minchin, P.R., O'Hara, R.B., Simpson, G.L., Solymos, P., Stevens, M.H., Szoecs, 
E., \& Wagner, H. (2019). vegan: Community Ecology Package (version 2.5.4, R Package). Retrieved from https://CRAN.R-project.org/package=vegan

Petersen, J.D., Reiners, S., \& Nault, B.A. (2013). Pollination services provided by bees in pumpkin fields supplemented with either Apis mellifera or Bombus impatiens or not supplemented. PLoS One, 8(7), e69819.

Pfister, S.C., Eckerter, P.W., Schirmel, J., Cresswell, J.E., \& Entling, M.H. (2017). Sensitivity of commercial pumpkin yield to potential decline among different groups of pollinating bees. Royal Society Open Science, 4(5), 170102.

Phillips, B.W., \& Gardiner, M.M. (2015). Use of video surveillance to measure the influences of habitat management and landscape composition on pollinator visitation and pollen deposition in pumpkin (Cucurbita pepo) agroecosystems. PeerJ, 3, e1342.

Potts, S.G., Biesmeijer, J.C., Kremen, C., Neumann, P., Schweiger, O., \& Kunin, W.E. (2010). Global pollinator declines: trends, impacts and drivers. Trends in Ecology \& Evolution, 25, 345-353.

Price, M.V., Waser, N.M., Irwin, R.E., Campbell, D.R., \& Brody, A.K. (2005). Temporal and spatial variation in pollination of a montane herb: a seven-year study. Ecology, 86(8), 2106-2116.

Reilly, J.R., Artz, D.R., Biddinger, D., Bobiwash, K., Boyle, N. K., Brittain, C., . . . Winfree, R. (2020). Crop production in the USA is frequently limited by a lack of pollinators. Proceedings of the Royal Society $B, 287(1931), 20200922$

Rosas-Guerrero, V., Aguilar, R., Martén-Rodríguez, S., Ashworth, L., Lopezaraiza-Mikel, M., Bastida, J.M., \& Quesada, M. (2014). A quantitative review of pollination syndromes: do floral traits predict effective pollinators? Ecology Letters, 17(3), 388-400.

Santiago-Hernández, M.H., Martén-Rodríguez, S., Lopezaraiza-Mikel, M., Oyama, K., González-Rodríguez, A., \& Quesada, M. (2019). The role of pollination effectiveness on the attributes of interaction networks: from floral visitation to plant fitness. Ecology, 100(10), e02803.

Serra, B.D., \& Campos, L.A.D.O. (2010). Polinização entomófila de abobrinha, Cucurbita moschata (Cucurbitaceae). Neotropical Entomology, 39(2), 153-159.

Shuler, R.E., Roulston, T.A.H., \& Farris, G.E. (2005) Farming practices influence wild pollinator populations on squash and pumpkin. Journal of Economic Entomology, 98(3), 790-795.

Vidal, M.D.G., Jong, D.D., Wien, H.C., \& Morse, R.A. (2006). Nectar and pollen production in pumpkin (Cucurbita pepo L.). Brazilian Journal of Botany, 29(2), 267-273.

Vidal, M.D.G., Jong, D.D., Wien, H.C., \& Morse, R.A. (2010). Pollination and fruit set in pumpkin (Cucurbita pepo) by honey bees. Brazilian Journal of Botany, 33(1), 106-113.

Waser, N.M., Chittka, L., Price, M.V., Williams, N.M., \& Ollerton, J. (1996). Generalization in pollination systems, and why it matters. Ecology, 77(4), 1043-1060.

Wcislo, W.T., Arneson, L., Roesch, K., Gonzalez, V., Smith, A., \& Fernández, H. (2004). The evolution of nocturnal behaviour in sweat bees, Megalopta genalis and M. ecuadoria (Hymenoptera: Halictidae): an escape from competitors and enemies? Biological Journal of the Linnean Society, 83(3), 377-387.

Wille, A. (1985). Las abejas Peponapis y Xenoglossa en Costa Rica y su importancia en la polinización de las Cucurbita domésticas. Revista de Biología Tropical, $33(1), 17-24$

Winfree, R., Reilly, J.R., Bartomeus, I., Cariveau, D.P., Williams, N.M., \& Gibbs, J. (2018). Species turnover promotes the importance of bee diversity for crop pollination at regional scales. Science, 359(6377), 791-793.

Zambrano, G., Gonzalez, V.H., Hinojosa-Diaz, I.A., \& Engel, M.S. (2013). Bees visiting squash (Cucurbita moschata Duchesne ex Poiret) in southwestern Colombia (Hymenoptera: Apoidea). Journal of Melittology, 18, 1-5. 